\title{
LA AUTONOMÍA PROGRESIVA DEL NIÑO Y SU PARTICIPACIÓN EN EL PROCESO JUDICIAL
}

\section{THE PROGRESSIVE AUTONOMY OF THE CHILD AND ITS PARTICIPATION IN THE JUDICIAL PROCESS}

William Homer Fernández Espinoza Abogado

Universidad de San Martín de Porres william_fernandez@usmp.pe

Perú

\section{SUMARIO}

- Introducción

- Descripción de la realidad problemática

- El niño como sujeto de derechos

- Interés superior del niño

- Autonomía progresiva del niño

- Acceso a la justicia del niño

- Participación del niño en el proceso de familia-civil

- Participación del niño en el proceso tutelar

- Participación del adolescente en conflicto con la ley penal

- Participación del niño en el proceso de violencia familiar y cuando es víctima de delitos o es testigo

- Participación judicial del niño con discapacidad y otras causas de vulnerabilidad

- Conclusiones

- Recomendaciones

\section{RESUMEN}

Esta investigación estudia el tema de la autonomía progresiva de las niñas, niños y adolescentes y los problemas sobre su participación en los diversos procesos en los que se ve involucrado, particularmente relacionados a su derecho de acceso a la justicia y el ejercicio de su derecho a ser escuchado en el ámbito judicial.

\begin{abstract}
This research studies the issue of the progressive autonomy of children and adolescents and the problems of their participation in the various processes in which they are involved, particularly related to their right of access to justice and the exercise of their right to be heard in the judicial sphere.
\end{abstract}

\section{PALABRAS CLAVE}

Acceso a la justicia, autonomía progresiva del niño, derecho del niño a ser escuchado, interés superior del niño, participación judicial del niño

\section{KEYWORDS}

Access to justice, progressive autonomy of the child, right of the child to be heard, best interest of the child, judicial participation of the child

\section{INTRODUCCIÓN}

Esta investigación aborda el problema de la participación de la niña, niño y adolescente en el proceso judicial frente a la vulneración de su derecho de acceso a la justicia y a ser escuchado en los tribunales a partir del informe del Comité de los Derechos del Niño sobre los avances del Perú para la implementación de lo dispuesto en la Convención sobre los Derechos del Niño de 1989, que reconoce internacionalmente al niño como un sujeto de derechos con autonomía progresiva y capacidad procesal en los asuntos 
que les afectan, en atención a su interés superior.

Para su elaboración, se estudió la doctrina y la legislación del sistema internacional de protección de los derechos humanos y el ordenamiento jurídico nacional sobre la materia y otros temas vinculados a este trabajo.

La investigación está divida en diversos puntos referidos a la descripción de la realidad problemática; el niño como sujeto de derechos; el interés superior del niño; la autonomía progresiva del niño; el acceso a la justicia del niño; la participación judicial del niño en diferentes materias; y finalmente se establecen las conclusiones y las recomendaciones del investigador.

\section{DESCRIPCIÓN DE LA REALIDAD PROBLEMÁTICA}

En el Perú según los datos otorgados por el Instituto Nacional de Estadística e Informática (INEI), al trimestre de octubre a diciembre de 2016 , el 58,8 \% de los hogares tiene entre sus miembros a alguna niña, niño y/o adolescente (INEI, 2017). De ellos un gran número participan o se encuentran involucrados en procesos judiciales en materia de familia-civil (separación y divorcio de los padres, alimentos, custodia, régimen de visitas), de familiatutelar (situación de riesgo o de desprotección familiar), de familia-penal (en conflicto con la ley penal), de violencia familiar o son víctimas de delitos o son testigos; que requieren tener garantizado su derecho fundamental a ser escuchados en el ámbito judicial.

El Código de los Niños y Adolescentes (en adelante CNA), aprobado por la Ley 27337 , señala en el artículo $99^{\circ}$ que la niña, el niño y el adolescente en condiciones de formarse sus propios juicios tienen derecho a manifestar libremente su opinión en todos los asuntos que les afectan y a que se consideren sus opiniones en función de su edad y madurez. Asimismo, el artículo 85. ${ }^{\circ}$ desarrolla el deber del juez de escuchar la opinión del niño y tomar en cuenta la del adolescente.

Estas disposiciones del CNA guardan concordancia con lo indicado en el artículo $12 .^{\circ}$ de la Convención sobre los Derechos del
Niño (1989)1, el cual desarrolla que los Estados Partes deben garantizar al niño el derecho de expresar su opinión libremente en todos los asuntos que le afectan; con tal fin, se le dará la oportunidad de ser escuchado en todo proceso judicial, ya sea directamente o por medio de un representante o de un órgano apropiado, en consonancia con las normas de procedimiento de la ley nacional. Ello en reconocimiento de la condición del niño como sujeto de derechos y ser humano con dignidad y con autonomía progresiva en la evolución de sus capacidades.

El Comité de los Derechos del Niño de las Naciones Unidas (en adelante el Comité), máximo órgano de interpretación de la Convención sobre los Derechos del Niño (en adelante la Convención), a través de su Observación General 12 (2009), expone que los Estados Partes deben garantizar el derecho a ser escuchado a todo niño que esté en condiciones de formarse un juicio propio. Estos términos no deben verse como una limitación, sino como una obligación para los Estados Partes de evaluar la capacidad del niño de formarse una opinión autónoma en la mayor medida posible. Eso significa que no pueden partir de la premisa de que un niño es incapaz de expresar sus propias opiniones. Por el contrario, deben dar por supuesto que el niño tiene capacidad para formarse sus propias opiniones y reconocer que tiene derecho a expresarlas. (párr. 20)

El Comité también resalta que el niño tiene derecho a no ejercer ese derecho. Para el niño, expresar sus opiniones es una opción, no una obligación. Por ello, los Estados Partes deben asegurarse de que el niño reciba toda la información y el asesoramiento necesarios para tomar una decisión que favorezca su interés superior. Tal obligación supone, con respecto al sistema judicial, el deber del Estado a garantizar directamente ese derecho o adoptar o revisar sus leyes para que el niño pueda disfrutarlo plenamente. (párr. 15-16)

El Protocolo Facultativo de la Convención sobre los Derechos del Niño relativo a un Procedimiento de Comunicaciones (2011) reconoce que la situación especial y de dependencia de los niños les puede dificultar seriamente el ejercicio de recursos para reparar

1 El Estado peruano, mediante la Resolución Legislativa 25278 del 4 de agosto de 1990, ratificó la Convención sobre los Derechos del Niño y entró en vigor el 4 de octubre de 1990. 
la violación de sus derechos. Por esto, el presente Protocolo refuerza y complementa los mecanismos nacionales al permitir a los niños denunciar la vulneración de sus derechos y tener acceso a recursos efectivos en sus países; así como exhortar a los Estados Partes a establecer procedimientos, adaptados al niño en todas las instancias, para garantizar la protección de sus derechos fundamentales.

Sin embargo, el 2 de marzo de 2016, el Comité de los Derechos del Niño emitió las Observaciones finales sobre los informes periódicos cuarto y quinto del Perú, en los que manifiesta su preocupación de que las niñas, niños y adolescentes son rara vez consultados en los procesos judiciales o se encuentran involucrados y no son fácilmente tenidos en cuenta ni reconocidos en los tribunales, como en sus hogares y en la comunidad, como consecuencia de concepciones tradicionales y culturales que aún se mantienen en nuestro país. (párr. 31)

Al respecto, se debe recordar que el Código Civil (1984) desarrolla en el artículo $43 .^{\circ}$ inciso 1 que son absolutamente incapaces los menores de dieciséis años de edad; y en el artículo $44 .^{\circ}$ inciso 1 que son relativamente incapaces los mayores de dieciséis y menores de dieciocho años de edad, sin embargo se les permite realizar aquellos actos determinados por la ley relacionados con las necesidades ordinarias de su vida diaria. Como observamos, el Código Civil todavía mantiene la figura del niño y del adolescente como incapaces, con un limitado ejercicio para celebrar ciertos actos, llegando a considerarlos como objetos de protección y no como sujetos de derechos, por su minoría de edad; disposiciones que si bien han sido derogadas tácitamente por el Código de los Niños y Adolescentes (2000), aún se mantienen expresas en dicho código, que vulnera el principio de autonomía progresiva del niño y perjudica su participación en un futuro proceso judicial.

Por otra parte, el Poder Judicial del Perú (2016) considera que el derecho del niño a ser oído no está garantizado de manera efectiva porque los procedimientos judiciales no han sido diseñados considerando las características específicas de la infancia. Asimismo, resalta que los operadores de justicia deben tener en cuenta que se presentan diversas barreras de acceso a la justicia cuando una niña, niño o adolescente participa en un proceso judicial; es decir, se encuentra enfrentado a un lenguaje complejo, inmerso en espacios ajenos a su experiencia e incluso intimidantes por estar vinculados con la justicia. Además, que si el niño no logra una participación efectiva en el proceso judicial, se estaría permitiendo su exclusión y valorando la problemática judicial desde una óptica adultocéntrica ${ }^{2}$.

Frente a este problema, se han aprobado una serie de normas, modificaciones y adecuaciones del ordenamiento jurídico nacional al sistema internacional de protección de los derechos humanos y las recomendaciones de sus máximos órganos con el fin de garantizar la protección del derecho del niño a ser escuchado en todos los procedimientos administrativos y procesos judiciales en los que participa $\mathrm{o}$ se encuentra involucrado. (Resolución Administrativa 228-2016-CE-PJ)

El 17 de junio de 2016, el Congreso de la República aprobó la Ley 30466 cuyo objeto es establecer los parámetros y garantías procesales para la consideración primordial del interés superior del niño en los procesos y procedimientos en los que estén inmersos los derechos de las niñas, niños y adolescentes; en el marco de lo establecido en la Convención sobre los Derechos del Niño y la Observación General 14 del Comité de los Derechos del Niño (2013). En tal sentido, el artículo $4^{\circ}$ de la referida ley reconoce que para la consideración primordial de su interés superior, el niño tiene derecho a expresar su propia opinión, con los efectos que la ley le otorga, lo cual es una garantía procesal.

Por su lado, el Ministerio de la Mujer y Poblaciones Vulnerables aprobó el Reglamento de la Ley 30364, ley para prevenir, sancionar y erradicar la violencia contra las mujeres y los integrantes del grupo familiar, mediante el Decreto Supremo 009-2016-MIMP (27 de julio de 2016), que en el artículo $17 .^{\circ}$ reconoce la capacidad procesal de las niñas, niños y adolescentes de denunciar actos de violencia en su agravio o en agravio de otras personas sin la necesidad de la presencia de una persona adulta.

2 Consideraciones contenidas en la Exposición de Motivos del Protocolo de Participación Judicial del Niño, Niña y Adolescente, aprobado por la Resolución Administrativa 228-2016-CE-PJ del Consejo Ejecutivo del Poder Judicial. 
Asimismo, debe destacarse la aprobación del Decreto Legislativo 1297 para la protección de niñas, niños y adolescentes sin cuidados parentales o en riesgo de perderlos $(30 \mathrm{de}$ diciembre de 2016), el cual desarrolla en el inciso f) del artículo 5. ${ }^{\circ}$ que la actuación estatal debe garantizar el ejercicio del derecho del niño a opinar, ser escuchado y que dicha opinión sea tomada en cuenta en todas las decisiones que se tomen; y en el artículo $7 .^{\circ}$ que antes de que se proceda a emitir la decisión sobre la situación de riesgo o desprotección familiar, incluso provisional, la autoridad competente debe escuchar, en su propio lenguaje, la opinión de la niña, niño o adolescente en una diligencia especial, teniendo en consideración su madurez y desarrollo, garantizando su intimidad, seguridad, la ausencia de coacción y el uso de métodos acordes a su edad, dejando constancia de ello en las resoluciones. Previamente, el niño debe recibir la información y asesoramiento necesarios que le permitan el ejercicio de este derecho en un lenguaje comprensible, en formatos accesibles y adaptados a sus circunstancias.

De igual manera, el Consejo Ejecutivo del Poder Judicial aprobó el Protocolo de Participación Judicial del Niño, Niña y Adolescente, a través de la Resolución Administrativa 228-2016-CE-PJ (31 de agosto de 2016), cuya finalidad es garantizar el derecho de las niñas, niños y adolescentes a ser oídos en los procesos judiciales que los afectan, desarrollando las disposiciones para tal ejercicio, la evaluación de su capacidad en atención a su edad y madurez, y las pautas para su representación. Asimismo, desarrolla el ejercicio del derecho a la información del niño, el cual es imprescindible para que este ejerza su derecho a ser oído; el derecho a la intimidad y a la privacidad de toda participación infantil; y los deberes y actuaciones del juez, los miembros del Equipo Multidisciplinario y de los servidores judiciales ${ }^{3}$. (Considerando tercero de la Resolución Administrativa 228-2016-CE-PJ)

No obstante estos avances normativos, aún quedan tareas pendientes contenidas en el Objetivo Estratégico N. ${ }^{\circ}$ 4: Garantizar la protección de las niñas, niños y adolescentes de 0 a 17 años de edad, sobre su participación en los asuntos que les involucran o interesan,

3 Considerando tercero de la Resolución Administrativa 228-2016-CE-PJ. del Plan Nacional de Acción por la Infancia y la Adolescencia 2012-2021 (PNAIA 2021); instrumento marco de política pública del Estado peruano para articular y vincular las políticas que se elaboren en materia de infancia y adolescencia en el país, hacia el desarrollo integral de las niñas, niños y adolescentes peruanos ${ }^{4}$ Asimismo, del Objetivo: Implementar medidas para garantizar el derecho a ser oído de las niñas, niños y adolescentes en los procesos judiciales, comprendido en el Eje 1: Niñas, Niños y Adolescentes del Plan Nacional de Acceso a la Justicia de Personas en Condición de Vulnerabilidad Poder Judicial 2016-2021 (PNAJPCV 2021) principal instrumento de gestión de este Poder del Estado para eliminar las barreras de acceso a la justicia e implementar las 100 Reglas de Brasilia de la Cumbre Judicial Iberoamericana.

Además, debemos tener en consideración las recomendaciones del Comité de los Derechos del Niño (2016) que, entre otros asuntos, exhorta al Estado peruano a velar que el derecho del niño a la participación en los asuntos pertinentes y a ser escuchado en las actuaciones judiciales quede garantizado en la legislación nacional, especialmente en la versión revisada del Código de los Niños y Adolescentes, cuyo texto se encuentra contenido en el Proyecto de Ley 495/2011-CR, el cual fue dictaminado por la Comisión de Justicia y Derechos Humanos y por la Comisión de la Mujer y Familia, pero que a la fecha no ha pasado al Pleno del Congreso de la República para su debate y posterior aprobación. Asimismo, que se establezcan directrices e indicadores de derechos humanos para facilitar, evaluar y supervisar la aplicación del derecho del niño a participar en asuntos pertinentes y a ser escuchado en los procesos judiciales. (párr. 32)

\section{EL NIÑO COMO SUJETO DE DERECHOS}

La Convención sobre los Derechos del Niño reconoce a las niñas, niños y adolescentes como sujetos plenos de derechos por lo que son titulares de todos los derechos inherentes

\footnotetext{
4 A través de la Ley 30362, se eleva a rango de ley el Decreto Supremo 001-2012-MIMP y declara de interés nacional y preferente atención la asignación de recursos públicos para garantizar el cumplimiento del plan nacional de acción por la infancia y la adolescencia - PNAIA 2012-2021.

5 Aprobado por el Consejo Ejecutivo del Poder Judicial a través de la Resolución Administrativa 090-2016-CE-PJ (7 de abril de 2016).
} 
a todas las personas, más derechos específicos en razón de su interés superior y por estar en un periodo de crecimiento (Beloff, 2004, p. 14); considerando en su preámbulo que, de conformidad con los principios proclamados en la Carta de las Naciones Unidas, la libertad, la justicia y la paz en el mundo se basan en el reconocimiento de la dignidad intrínseca y de los derechos iguales e inalienables de todos los seres humanos.

Esta premisa fue considerada previamente en la Declaración de los Derechos del Niño (1959) en la cual se reafirma la protección de los derechos fundamentales de las niñas, niños y adolescentes por su condición de dignidad, igualdad y valor de persona humana; enunciado en la Declaración de Ginebra sobre los Derechos del Niño (1924) y reconocida por la Declaración Universal de los Derechos Humanos (1948).

Al respecto, Miguel Cillero Bruñol (2004) expone que la Convención no es meramente una reafirmación de los derechos del niño como persona humana, sino una especificación de estos derechos para las particulares circunstancias de la vida de las niñas, niños y adolescentes, también, es fuente de derechos propios de la infancia y de una serie de principios que regulan la protección conjunta de los derechos de los niños y los adultos, y sus derechos y deberes recíprocos. (p. 82)

La Comisión Interamericana de Derechos Humanos, en sus intervenciones escritas y orales durante la elaboración de la Opinión Consultiva OC-17/2002 (28 de agosto de 2002), sobre la condición jurídica y derechos humanos del niño, manifestó que con la aprobación de la Convención sobre los Derechos del Niño se construyó el llamado modelo o doctrina de la protección integral de los derechos de las niñas, niños y adolescentes. Este nuevo sistema se caracteriza por reconocer a los niños como sujetos de derechos y la necesidad de brindarles medidas especiales de protección, las cuales deben impedir intervenciones ilegítimas del Estado que vulneren sus derechos, y prever prestaciones positivas que les permitan disfrutar efectivamente de los mismos. (p. 20)

Para mayor abundamiento, Mary Beloff (2004) comenta que a través de esta doctrina surge una nueva concepción sobre la protección de los derechos de los niños, que se constituyó a través de diversos instrumentos específicos, regionales y universales de protección de los derechos humanos, que representan la expresión de acuerdos e intenciones de la comunidad internacional en esta materia. Se crearon nuevos estándares en relación con la condición jurídica de la infancia que reconoce a la niña, el niño y el adolescente como sujetos plenos de derechos y libertades. (pp. 31-33)

Por otro lado, se debe resaltar que el Comité de los Derechos del Niño, en sus diferentes observaciones generales, recuerda que la Convención desarrolla la definición del concepto de niño en su artículo 1, indicando que se entiende por niño a todo ser humano menor de dieciocho años de edad, salvo que, en virtud de la ley de cada país, haya alcanzado antes la mayoría de edad. Asimismo, en su artículo 2 dispone que los Estados Partes deben asegurar la aplicación de los derechos enunciados en la Convención a cada niño sujeto a su jurisdicción, adoptando las medidas apropiadas para garantizar que el niño esté protegido contra cualquier forma de vulneración de sus derechos.

De acuerdo con el informe de la Comisión Interamericana de Derechos Humanos y la Organización de Estados Americanos, sobre el derecho del niño a la familia (17 de octubre de 2013), esta protección especial se fundamenta en el reconocimiento de las condiciones especiales del niño quien, debido a su desarrollo progresivo en todas sus facetas, a nivel físico, cognitivo, emotivo, psicológico y social, depende de los adultos para el efectivo acceso y disfrute de todos sus derechos, así como para el ejercicio de las acciones jurídicas tendientes a exigir los mismos. Esta dependencia de los adultos, y su intensidad, se ve modificada de acuerdo con la evolución de las capacidades del niño y grado de madurez. Así, para asegurar sus derechos más fundamentales los niños dependen directamente de los adultos para recibir la atención y los cuidados necesarios, en particular en las primeras etapas de su vida. (párr. 42)

En el Perú, el 3 de agosto de 1990, por medio de la Resolución Legislativa 25278, la Convención de los Derechos del Niño fue aprobada y ratificada por el Congreso de la República. Es así que nace una imperiosa necesidad de promover una legislación más realista $\mathrm{y}$ acorde con estos nuevos requerimientos. Los 
compromisos internacionales en favor de la infancia fueron consolidando la urgente necesidad de dar al país un nuevo texto sobre la niñez, en reemplazo del Código de Menores de 1962, el cual es dado el 24 de diciembre de 1992 a través del denominado Código de los Niños y Adolescentes, aprobado por el Decreto Ley 26102 (Aguilar, 1996, pp. 435-436).

El actual Código de los Niños y Adolescentes (2000) define al niño en el artículo I del Título Preliminar, recogiendo lo señalado por la Convención en el artículo 1, pero hace una distinción al considerar al niño como todo ser humano desde su concepción hasta cumplir los doce años de edad y al adolescente desde los doce hasta cumplir los dieciocho años de edad. Asimismo, en su artículo II indica que el niño y el adolescente son sujetos de derechos, libertades y de protección específica; y en su artículo IV que además de los derechos inherentes a la persona humana, el niño y el adolescente gozan de los derechos específicos relacionados con su proceso de desarrollo.

\section{INTERÉS SUPERIOR DEL NIÑO}

El interés superior del niño fue previsto en la Declaración de los Derechos del Niño, en el principio II, en el cual enuncia que este gozará de una protección especial y dispondrá de oportunidades y servicios, dispensado todo ello por la ley y por otros medios, para que pueda desarrollarse física, mental, moral, espiritual y socialmente en forma saludable y normal, así como en condiciones de libertad y dignidad. Asimismo, enfatiza que al promulgar leyes con este fin, la consideración fundamental a la que se atenderá será el interés superior del niño.

Posteriormente, la Convención sobre los Derechos del Niño recoge este enunciado y declara en el artículo 3. ${ }^{\circ}$ que en todas las medidas concernientes a las niñas, niños y adolescentes que tomen las instituciones públicas o privadas de bienestar social, los tribunales, las autoridades administrativas o los órganos legislativos, una consideración primordial a que se atenderá será el interés superior del niño. Asimismo, los Estados Partes se comprometen a asegurar al niño la protección y el cuidado que sean necesarios para su bienestar, teniendo en cuenta los derechos y deberes de sus padres, tutores $\mathrm{u}$ otras personas responsables de él ante la ley $\mathrm{y}$, con ese fin, tomarán todas las medidas legislativas $\mathrm{y}$ administrativas necesarias a través de una supervisión adecuada.

Al respecto, el Comité de los Derechos del Niño, a través de su Observación General 14, explica que el artículo $3 .^{\circ}$ de la Convención otorga al niño el derecho a que se considere y tenga en cuenta de manera primordial su interés superior en todas las medidas o decisiones que le afecten, tanto en la esfera pública como en la privada. Además, que esa disposición establece uno de los valores fundamentales de la Convención; es uno de los cuatro principios generales en lo que respecta a la interpretación de todos los derechos del niño, y lo aplica como un concepto dinámico que debe evaluarse adecuadamente en cada contexto (párr. 1).

El Comité plantea que el objetivo del concepto de interés superior del niño (como derecho sustantivo, principio jurídico interpretativo fundamental y norma de procedimiento) (párr. 6) es garantizar el disfrute pleno y efectivo de todos los derechos reconocidos por la Convención y el desarrollo holístico del niño. Recuerda además que en la Convención no hay una jerarquía de derechos; todos los derechos previstos responden al interés superior del niño y ningún derecho debería verse perjudicado por una interpretación negativa sobre este principio. (párr. 4)

En otras palabras, el concepto de este principio rector, cuyo origen surge del derecho común, comenta Daniel O'Donnell (1990) significa esencialmente que cuando se presenta algún tipo de conflicto de interés entre un niño y otra persona adulta, prevalecen los intereses del niño sobre los de otras personas o instituciones para favorecer la protección de sus derechos. (p. 19)

Por consiguiente, agrega el Comité, aunque el concepto de interés superior del niño es complejo, también es flexible y adaptable y su contenido debe determinarse caso por caso. Debe ajustarse y definirse de forma individual, con arreglo a la situación concreta del niño o los niños afectados y teniendo en cuenta el contexto, la situación y las necesidades personales. En lo que respecta a las decisiones particulares, se debe evaluar y determinar el interés superior del niño en función de las circunstancias específicas de cada niño en concreto. En cuanto a las decisiones colectivas, se debe evaluar y determinar el 
interés superior del niño en general atendiendo a las circunstancias del grupo concreto $o$ los niños en general. En ambos casos, la evaluación y la determinación deben llevarse a cabo respetando plenamente los derechos que figuran en la Convención. (párr. 32)

En nuestro país, el Código de los Niños y Adolescentes se adhiere a lo dispuesto por la Convención, señalando en el artículo IX del Título Preliminar que en toda medida concerniente a la niña, el niño y al adolescente que adopte el Estado a través de los Poderes Ejecutivo, Legislativo y Judicial, del Ministerio Público, los gobiernos regionales, gobiernos locales y sus demás instituciones, así como en la acción de la sociedad, se considerará el principio del interés superior del niño y el respeto a sus derechos.

Adicionalmente, se debe resaltar la promulgación de la Ley 30466, ley que establece los parámetros y garantías procesales para la consideración primordial del interés superior del niño en los procesos y procedimientos en los que estén inmersos los derechos de las niñas, niños y adolescentes.

En el aspecto judicial, se debe resaltar que el artículo $4 .^{\circ}$ de la Ley 30466 señala que para la consideración primordial del interés superior del niño, los operadores de justicia deben tomar en cuenta, como garantías procesales: el derecho del niño a expresar su propia opinión; la determinación de los hechos, con la participación de profesionales capacitados para evaluar el interés superior del niño; la percepción del tiempo, por cuanto la demora de los procesos y procedimientos afecta la evolución de los niños; la participación de profesionales cualificados; la representación letrada del niño con la autorización respectiva de los padres, según corresponda; la argumentación jurídica de la decisión tomada en la consideración primordial del interés superior del niño; los mecanismos para examinar o revisar las decisiones concernientes a los niños; y la evaluación del impacto de la decisión tomada en consideración de los derechos humanos del niño.

\section{AUTONOMÍA PROGRESIVA DEL NIÑO}

Miguel Cillero Bruñol (1998) expone que otra característica fundamental del enfoque de los derechos humanos aplicado a la infancia es constituir una nueva concepción del niño y de sus relaciones con la familia, la sociedad y el Estado. Esta nueva concepción se basa en el reconocimiento expreso del niño como sujeto de derecho en oposición a la idea predominante de niño definido a partir de su incapacidad jurídica. (pág. 4)

Para Aída Kemelmajer y Mariel Molina (2015) el nuevo régimen de capacidad prescinde del tradicional binomio capacidad-incapacidad y se asienta en el principio constitucionalconvencional de la autonomía progresiva de la niña, niño y adolescente para el ejercicio pleno de sus derechos, contenidos en los artículos 3. ${ }^{\circ}, 5 .^{\circ}$ y $12 .^{\circ}$ de la Convención sobre los Derechos del Niño y la Opinión Consultiva OC-17/2002 de la Corte Interamericana de Derechos Humanos.

El artículo 5. ${ }^{\circ}$ de la Convención indica que los Estados Partes respetarán las responsabilidades, los derechos y los deberes de los padres o, en su caso, de los miembros de la familia ampliada o de la comunidad, según establezca la costumbre local, de los tutores $\mathrm{u}$ otras personas encargadas legalmente del niño de impartirle, en consonancia con la evolución de sus facultades, la dirección y orientación apropiadas para que el niño ejerza los derechos reconocidos en la presente Convención.

Al respecto, Silvia Laino Pereyra (2012) comenta que en la medida en que desarrolla sus capacidades y de acuerdo con su edad, el niño toma control sobre ámbitos competenciales de representación o sustitución delegados a sus padres o al Estado, es decir, adquiere una autonomía progresiva para el ejercicio de sus derechos. (p. 22)

Por otro lado, el artículo $12 .^{\circ}$ de la Convención resalta que los Estados Partes garantizarán a la niña, niño y adolescente, que esté en condiciones de formarse un juicio propio, el derecho de expresar su opinión libremente en todos los asuntos que le afectan, teniéndose debidamente en cuenta sus opiniones, en función de la edad y madurez.

Sobre lo anterior, el Comité de los Derechos del Niño, mediante su Observación General 12, expone que los Estados Partes deben partir de la premisa de que un niño tiene la capacidad de formarse una opinión autónoma, en la mayor medida posible, y que este tiene 
el derecho de expresar dichas opiniones. Por esto, el Comité exhorta a los Estados Partes a no imponer ningún límite de edad al niño para expresar su opinión libremente, pues ello se da en consideración también de su propia madurez. (párrs. 20-21)

Además, el Comité, a través de la Observación General 14, resalta que el hecho de que el niño sea muy pequeño o se encuentre en una situación vulnerable (por ejemplo, tiene alguna discapacidad, pertenece a pueblos indígenas o grupos minoritarios, es migrante o pobre) no lo priva del derecho a expresar su opinión, ni reduce la importancia que debe concederse a sus opiniones al determinar el interés superior. La adopción de medidas concretas para garantizar el ejercicio en pie de igualdad de los derechos de los niños en ese tipo de situaciones debe someterse a una evaluación individual que dé una función a los propios niños en el proceso de toma de decisiones y permitan introducir ajustes razonables y prestar el apoyo necesario para garantizar su plena participación en la evaluación de su interés superior. (párr. 54)

Fermín Chunga Lamonja (2012) aclara que desde que el momento en que el niño puede expresarse tiene derecho a manifestar su propia opinión y desde que es adolescente tiene un razonamiento cabal, por ello tal opinión debe ser obligatoriamente tomada en cuenta por la autoridad judicial que mantenga competencia sobre un proceso en el que estén involucrados menores de edad. (p. 399)

Además, Giménez de Allen (2010) resalta que el juez debe valorar la autenticidad de las manifestaciones del niño, debido a que muchas veces estas son influenciadas o manipuladas por uno de sus progenitores, por lo que sus opiniones no nacen de ellos mismos sino de terceros, que son los mismos padres o miembros de su entorno. La falta de cumplimiento del derecho del niño a ser oído dentro del proceso judicial debe ser sancionada con la nulidad del mismo. (pp. 99-101)

En consecuencia, Mary Beloff (2004) sostiene que se reconoce al niño como titular de todos los derechos inherentes a todas las personas, más derechos específicos por encontrarse en un periodo de crecimiento. No obstante, estos derechos le son limitados por diversas razones como su falta de madurez, capacidad para formar un juicio propio, su desarrollo emocional o su interés superior. A esto se suma que, por la evolución de sus facultades, va adquiriendo la autonomía para el ejercicio de aquellos derechos. (p. 14)

En el Perú, el artículo IV del Título Preliminar del Código de los Niños y Adolescentes desarrolla que además de los derechos inherentes a la persona humana, la niña, niño y adolescente gozan de los derechos específicos relacionados con su proceso de desarrollo. Tienen capacidad especial para la realización de los actos civiles autorizados por este Código y demás leyes. Asimismo, establece las circunstancias en que el ejercicio de esos actos requiere de un régimen de asistencia y determina responsabilidades.

\section{ACCESO A LA JUSTICIA DEL NIÑO}

María de Jesús Conde (2009) señala que el acceso a la justicia hace referencia a un conjunto de derechos y garantías que los Estados tienen que asegurar a sus ciudadanos, sin ningún tipo de distinción, para que puedan acudir a la administración de justicia a resolver un conflicto y obtener una sentencia justa, de conformidad con el ordenamiento jurídico interno de cada país. (p. 191)

Juan E. Méndez (2000) expone que el acceso a la justicia no es una problemática de aparición reciente, pues se trata de un concepto que ha sufrido profundas transformaciones en las últimas décadas, al ser una concepción que involucra el deber estatal de proporcionar un servicio público, protector no solo de los derechos individuales, sino también de los derechos colectivos caracterizados por la presencia de los intereses difusos. Asimismo, destaca que el sistema de administración de justicia constituye la última frontera donde los ciudadanos perciben si sus derechos son efectivamente respetados y garantizados; de ahí la imperiosa necesidad de facilitar y favorecer, no solo el acceso a la justicia, sino un acceso efectivo a la misma. (p. 17)

La Convención Americana sobre Derechos Humanos (1969) dispone en el artículo 8..$^{\circ}$ que toda persona tiene derecho a ser oída, con las debidas garantías y dentro de un plazo razonable, por un juez o tribunal competente, independiente e imparcial, para la determinación de sus derechos y obligaciones de orden civil, laboral, fiscal o de cualquier 
otro carácter. Además, durante el proceso, toda persona tiene derecho, en plena igualdad, a ser asistido gratuitamente por un traductor o intérprete, si no comprende o no habla el idioma del juzgado; a la comunicación previa y detallada del proceso; al tiempo y de los medios adecuados para la preparación de su defensa; a defenderse personalmente o de ser asistido por un defensor de su elección y de comunicarse libre y privadamente con su defensor; y derecho de recurrir ante un tribunal superior.

Sharon Detrick (2015), a través de su artículo sobre el acceso a la justicia para todos los niños y niñas del mundo para UNICEF, define al acceso a la justicia como la posibilidad de obtener una justa y oportuna reparación a las violaciones de derechos tal como se proponen en las normas y criterios nacionales e internacionales, incluida la Convención sobre los Derechos del Niño. En esencia, sostiene que todas las personas deben tener la posibilidad de hacer reclamos $\mathrm{y}$ de exigir responsabilidad cuando no se respetan sus derechos. Para niños y adultos por igual, el derecho al acceso a la justicia es un derecho humano fundamental $\mathrm{y}$, además, un prerrequisito esencial para la protección y promoción de todos los otros derechos.

La Corte Interamericana de Derechos Humanos, a través de la Opinión Consultiva OC-17/2002, manifiesta que las condiciones en las que participa un niño en un proceso no son las mismas en que lo hace un adulto. Si se sostuviera otra cosa se desconocería la realidad y se omitiría la adopción de medidas especiales para la protección de los niños, con grave perjuicio para ellos. Por lo tanto, recalca, es indispensable reconocer y respetar las diferencias de trato que corresponden a diferentes situaciones, entre quienes participan en un procedimiento. (párr. 96)

No obstante, en el ejercicio y disfrute de este derecho, las niñas, niños y adolescentes se enfrentan a los mismos obstáculos que los adultos, tales como el acceso a un recurso, al juez o a los tribunales; procesos realizados fuera de un plazo razonable o dilataciones indebidas; falta de información sobre la participación en el proceso judicial y restricción de su participación en el proceso; no considerar las opiniones en atención a la edad, desarrollo integral e interés superior; salas inadecuadas para la celebración de los actos judiciales; formalismos innecesarios en los tribunales; no utilizar un lenguaje judicial claro y sencillo; falta de motivación de las decisiones judiciales; e incumplimiento de sentencias y falta de reparaciones frente a la vulneración de derechos.

Sharon Detrick (2015), complementando este argumento, manifiesta que la condición especial y dependiente de los niños presenta dificultades añadidas, entre ellas problemas relacionados con la falta de capacidad legal para hacer denuncias o iniciar procedimientos jurídicos. Los niños pobres y marginados están en particular desventaja por sus condiciones de vulnerabilidad enfocadas en la edad y la situación económica de ellos, sus familias o representantes.

Al respecto, es importante referirnos que en la Declaración de Brasilia, suscrita al término de la XIV edición de la Cumbre Judicial Iberoamericana, llevada a cabo en Brasil (2008), los presidentes de los Poderes Judiciales de Iberoamérica aprobaron las Reglas de Brasilia sobre el Acceso a la Justicia de las Personas en Condición de Vulnerabilidad con el objetivo de garantizar el efectivo acceso a la justicia de aquellas personas que por razón de su edad, género, estado físico o mental, o por sinsustancias sociales, económicas y/o culturales, encuentran especiales dificultades para ejercitar con plenitud ante el sistema de justicia sus derechos reconocidos en el ordenamiento jurídico. El Poder Judicial del Perú se adhirió a las mencionadas Reglas de Brasilia a través de la Resolución Administrativa 266-2010-CE-PJ (26 de junio de 2010).

Dichas Reglas desarrollan que para el efectivo acceso a la justicia para la defensa de los derechos, los funcionarios $\mathrm{y}$ operadores del sistema de justicia promoverán las condiciones necesarias para brindar asistencia legal de calidad, especializada y gratuita y defensa pública, ágil y prioritaria; derecho a un intérprete; promoción de la oralidad y el uso de formularios accesibles; actuación interdisciplinaria; prestar información antes, durante y después del juicio para la comprensión de los actos judiciales y de la sentencia; redactar las resoluciones en un lenguaje claro y sencillo; accesibilidad a las instalaciones judiciales; y la reserva en las actuaciones para la protección de la intimidad e imagen de las personas. 
La Regla de Brasilia 5 reconoce a la niña, niño y adolescente como una persona en condición de vulnerabilidad y que debe ser objeto de una especial tutela por parte de los órganos del sistema de justicia en consideración a su desarrollo evolutivo. Asimismo, la Regla de Brasilia 78 recomienda que en los actos judiciales en los que participen niños se debe tener en cuenta su edad y desarrollo integral, y en todo caso: se deberá celebrar en una sala adecuada; se facilitará la comprensión, utilizando un lenguaje sencillo; se evitarán todos los formalismos innecesarios, tales como la toga, la distancia física con el tribunal y otros similares. Además, las Reglas de Brasilia 81 y 82 prohíben la toma y difusión de imágenes, ya sea en fotografía o en vídeo, en aquellos supuestos en los que pueda afectar de forma grave la dignidad, a la situación emocional o a la seguridad de la niña, niño o adolescente.

Aída Kemelmajer y Mariel Molina (2015) exponen que cuando las pretensiones involucran los intereses de niños o adolescentes normalmente existe algún tipo de participación procesal. Sostienen que puede intervenir en forma directa si cuenta con edad y grado de madurez para hacerlo. Si no puede comprender el contenido y sentido de los actos, lo hará en forma indirecta, a través de su representante legal; sin embargo, aún en estos casos, se les reserva un espacio de actuación propia. Es decir, ser parte procesal es una de las diversas formas que puede implicar la presencia de la niña, niño y adolescente en un proceso, pero no la única, pues su peculiar condición impone al sistema jurídico habilitar $\mathrm{y}$, en algunos casos promover, otras posibles formas de intervención. (p. 5)

En nuestro país, como se comentó, el Poder Judicial aprobó el Protocolo de Participación Judicial del Niño, Niña y Adolescente (2016), implementando las Reglas de Brasilia, cuyo ámbito de aplicación es garantizar el derecho del niño a ser oído en todos los procesos judiciales que le afectan: divorcios e invalidez matrimonial de los padres, custodia, régimen de visitas, autorización de viajes, autorización para enajenar bienes, acogimiento familiar, adopción por excepción, suspensión, pérdida y extinción de la patria potestad, violencia física, psicológica, sexual o económica; niños y adolescentes en conflicto con la ley penal; abusos sexuales, delitos en perjuicio de los niños, entre otros.
Es importante resaltar que, la disposición 3 del referido Protocolo desarrolla el derecho del niño a ser informado, señalando que este es un derecho imprescindible para que la niña, niño y adolescente ejerza su derecho a ser oído en el proceso judicial. Para ello, el juez debe disponer que se prepare debidamente al niño antes de que este sea escuchado y que se nombre a una persona de apoyo que lo asista, pudiendo tratarse de un especialista del Equipo Multidisciplinario. Además, tal preparación debe realizarse por lo menos un día previo a la diligencia judicial prevista, mediante una conversación, a fin de que se le explique, de acuerdo con su edad y grado de desarrollo, la naturaleza y el propósito de la diligencia en que participará.

Asimismo, la disposición 4 del Protocolo indica las pautas para el ejercicio del derecho a la información del niño durante la actuación judicial, como que deberán ser informados de forma completa, accesible, de acuerdo con su diversidad y apropiada a su edad, en un lenguaje claro y sencillo sobre el proceso judicial, el rol que les toca desempeñar, la importancia de su participación, alcance, propósito y posible repercusión, condiciones en que se le pedirá que exprese sus opiniones, y la opción de comunicar su opinión directamente o por medio de un presentante.

De otra parte, el Protocolo señala en su considerando 6 que es deber del juez la obligación de evaluar la capacidad del niño a formarse una opinión autónoma, teniendo en cuenta criterios cronológicos, psicológicos, culturales y sociales; para lo cual podrá requerir asistencia especializada; debiendo tener en cuenta la opinión del niño como factor destacado en la resolución judicial, siempre que el niño esté en condiciones de formarse un juicio propio de manera razonable e independiente.

Además, sobre la presunción de capacidad, en su considerando 9, el juez no puede partir de la premisa de que un niño es incapaz de expresar sus propias opiniones; se debe presumir que el niño tiene capacidad para formarse sus propias opiniones y reconocer que tiene derecho a expresarlas. No corresponde al niño probar primero que tiene la capacidad de formarse un juicio propio. 


\section{PARTICIPACIÓN DEL NIÑO EN EL PROCESO DE FAMILIA-CIVIL}

Sobre el derecho de la niña, niño y adolescente a ser escuchado y su participación en el proceso civil, el Comité de los Derechos del Niño, a través de su Observación General 12, explica que en los casos de separación o divorcio, los hijos de la pareja resultan afectados por las decisiones de los tribunales. El juez determina las cuestiones relativas a la manutención del niño, la custodia y el acceso, ya sea en un juicio o por mutuo acuerdo de los padres. Muchas jurisdicciones han incluido en sus legislaciones, respecto de la disolución de una relación, una disposición por la que el juez debe otorgar especial consideración al interés superior del niño. (párr. 51)

El Comité sostiene que por ese motivo todas las leyes sobre separación y divorcio deben incluir el derecho del niño a ser escuchado por las autoridades que adoptan tales decisiones. Algunas jurisdicciones, por motivos de política o de legislación, prefieren indicar una edad en que el niño es considerado capaz de expresar sus propias opiniones. Sin embargo, la Convención sobre los Derechos del Niño prevé que este asunto se determine caso por caso, ya que se refiere a la edad y la madurez, por lo que exige una evaluación individualizada de la capacidad de la niña, niño o adolescente. (párr. 52)

En los casos de la separación de los padres y las formas sustitutivas de cuidado, el Comité señala que cuando se adopte la decisión de apartar a un niño de su familia porque este es víctima de abusos o negligencia en su hogar, debe tenerse en cuenta la opinión del niño para determinar su interés superior. En la experiencia del Comité, resalta, los Estados Partes no siempre tienen en cuenta el derecho del niño a ser escuchado. Por ello, recomienda que se garantice, mediante leyes, normas y directrices de política, que se recaben y se tengan en cuenta las opiniones del niño, en particular en las decisiones relativas a su asignación a hogares de acogimiento familiar o de guarda, la elaboración y revisión de planes de guarda y las visitas a los padres y la familia. (párrs. 53-54)

La Comisión Interamericana de Derechos Humanos, a través del informe sobre el derecho del niño y la niña a la familia (2013), explica que en las medidas que implican la separación de la familia, se aplican los principios de necesidad, excepcionalidad y temporalidad en relación a la eventual separación de un niño de su familia por motivos de protección, establecidos en particular por la Convención sobre los Derechos del Niño. (párr. 67)

El artículo 9. ${ }^{\circ}$ de la Convención expresa que los Estados Partes velarán por que el niño no sea separado de sus padres contra la voluntad de estos, excepto cuando, a reserva de revisión judicial, las autoridades competentes determinen, de conformidad con la ley y los procedimientos aplicables, que tal separación es necesaria en el interés superior del niño. Tal determinación puede ser necesaria en casos particulares, por ejemplo, en los casos en que el niño sea objeto de maltrato o descuido por parte de sus padres o cuando estos viven separados y debe adoptarse una decisión acerca del lugar de residencia del niño. En todo caso, se respetará el derecho del niño que esté separado de uno o de ambos padres a mantener relaciones personales y contacto directo con ambos padres de modo regular, salvo si ello sea contrario al interés superior del niño.

La Comisión Interamericana continúa, precisando, que en las Directrices sobre las modalidades alternativas de cuidado de los niños (2010) se han fijado pautas adecuadas de orientación política y práctica relativas a la protección y al bienestar de los niños privados del cuidado parental o en riesgo de perderlo, basadas también en los principios de excepcionalidad y temporalidad antes mencionados. (párr. 67)

El CNA, en los procesos de custodia y de régimen de visitas, dispone en el artículo 85 . - que el juez especializado debe escuchar la opinión del niño y tomar en cuenta la del adolescente, en concordancia con lo expresado en el artículo $9 .^{\circ}$ del mismo Código y de igual manera en el artículo 9. de la Convención sobre los Derechos del Niño.

Al respecto, el Protocolo de Participación Judicial del Niño, Niña y Adolescente del Poder Judicial guarda concordancia también con lo señalado en el párrafo anterior, indicando en su primera disposición que el niño tiene derecho a ser oído y a expresar su opinión en sus propias palabras sobre las decisiones que le afecten, y a que sus puntos de vista sean tomados en consideración según sus aptitudes, 
edad, madurez intelectual y evolución de su capacidad. Asimismo, que tiene el derecho a expresar su opinión libremente, sin presión ni manipulación de las personas adultas; y pueden escoger si quieren ejercer ese derecho o no. En tal sentido, el juez debe evitar en toda participación del niño que tenga contacto con cualquier persona adulta que pueda afectar su integridad emocional y su libre actuación en el proceso judicial.

Sin embargo, pese a estas pautas, en los procesos de custodia y de régimen de visitas, se presenta un problema relacionado con la conducta obstruccionista y de manipulación de uno de los progenitores, quien tiene la custodia temporal, que de manera reiterada e injustificada lo realiza con la finalidad de perjudicar la relación personal, el contacto directo y la comunicación permanente del hijo con el otro progenitor; esta problemática ha sido denominada por la doctrina jurídica como alienación parental, que en su forma más grave se termina por manipular las opiniones del niño, generándose el síndrome de alienación parental. (Fernández, 2016, p.2)

No obstante, el Poder Judicial, frente a esta dificultad, ha implementado el Protocolo de actuación para la comunicación entre los jueces de familia y los Equipos Multidisciplinarios, y el Protocolo de actuación del Equipo Multidisciplinario de los Juzgados de Familia, aprobados a través de la Resolución Administrativa 027-2016-CE-PJ (3 de febrero de 2016) para coadyuvar a la mejora de la celeridad en beneficio de los usuarios de los procesos judiciales de familia con la estandarización del proceso de evaluación a cargo de los profesionales del Equipo Multidisciplinario, mejorando la eficiencia y la toma oportuna de decisiones.

\section{PARTICIPACIÓN DEL NIÑO EN EL PROCESO TUTELAR}

Uno de los principales problemas relacionados con la participación de la niña, niño y adolescente en el proceso tutelar es la gran inseguridad jurídica generada por la no desconcentración de las Unidades de Investigación Tutelar del Ministerio de la Mujer y Poblaciones Vulnerables (MIMP), debido a que en la mayoría de provincias del país, el Poder Judicial, a través de sus jueces de familia o mixtos, asume esta competencia. (Castro, 2013, p. 24)

A la fecha, el MIMP se encuentra desconcentrado en Arequipa, Cusco, Junín, Lima, Lima Este, Lima Norte/Callao, Madre de Dios y Piura.

Según los datos otorgados por su Dirección de Investigación Tutelar, en el período 2013 a marzo de 2017, existen 34,999 niñas, niños $\mathrm{y}$ adolescentes ingresados al servicio de investigación tutelar; 7,339 niños con situación tutelar resuelta; 4,968 niños reintegrados en un entorno familiar; 318 niños remitidos al Poder Judicial con informe final; y 239 niños con declaración de abandono.

Sin embargo, a partir del Informe 153 de la Defensoría del Pueblo (2011), se calcula que en nuestro país existen aproximadamente 17 mil niñas, niños y adolescentes en situación de desprotección familiar; cifra que no recoge el gran número de niños que se encuentran en las calles como producto de graves problemas de desestructuración familiar que, en muchos casos, tienen la pobreza como telón de fondo.

En la legislación nacional, el 30 de diciembre de 2016, se aprobó el Decreto Legislativo 1297, para la protección de niñas, niños y adolescentes $\sin$ cuidados parentales o en riesgo de perderlos, el cual desarrolla, en el artículo $5 .^{\circ}$, el deber de garantizar el ejercicio del derecho del niño a opinar, ser escuchado y que dicha opinión sea tomada en cuenta en todas las decisiones que se tomen. Asimismo, en el artículo $7 .{ }^{\circ}$ que antes de que se proceda a emitir la decisión sobre la situación de riesgo o desprotección familiar, incluso provisional, la autoridad competente debe escuchar, en su propio lenguaje, la opinión del niño en una diligencia especial, teniendo en consideración su madurez y desarrollo garantizando su intimidad, seguridad, la ausencia de coacción y el uso de métodos acordes a su edad, dejando constancia de ello en las resoluciones. Previamente, es importante que la niña, niño y adolescente reciba la información y asesoramiento necesario que le permita el ejercicio de este derecho en un lenguaje comprensible, en formatos accesibles y adaptados a sus circunstancias especiales.

Por otro lado, el Protocolo de Participación Judicial del Niño, Niña y Adolescente del 
Poder Judicial, precisa, en la disposición 14, que cuando se haya previsto para un niño el acogimiento familiar y la adopción por excepción, es de vital importancia que el niño sea escuchado.

Todo lo anterior guarda concordancia con lo dispuesto en las Directrices sobre las modalidades alternativas de cuidado de los niños, de Naciones Unidas, que señalan que se debe velar para que el niño tenga acceso a representación legal y a otro tipo de asistencia si fuera necesario; que este sea oído de modo que sus opiniones sean tenidas en cuenta por las autoridades encargadas de la toma de decisiones; y que el niño sea informado y asesorado sobre sus derechos. (párr. 103)

\section{PARTICIPACIÓN DEL ADOLESCENTE EN CONFLICTO CON LA LEY PENAL}

Emilio García Méndez (2004) comenta que con la doctrina de la situación irregular, cuyos principios inspiraron a todas las legislaciones de menores hasta antes del siglo $\mathrm{XX}$, se legitimaban las acciones judiciales indiscriminadas en contra de los niños y los adolescentes, criminalizando la pobreza y la situación de abandono en la que se encontraban, y con ello se privilegiaba su institucionalización y se centralizaba el poder de decisión en el juez de menores. Este paradigma, posteriormente, fue sustituido por la doctrina de la protección integral de los derechos de las niñas, niños y adolescentes. (pp. 6-7)

Actualmente, el adolescente como sujeto de derecho y obligaciones tiene la capacidad de comprender sus actos, y por lo mismo, ser responsable de estos. A diferencia de los adultos que han alcanzado un desarrollo bio-sicosocial integral, los adolescentes se encuentran en una etapa de formación, por lo cual su responsabilidad es especial. En este sentido, mientras a los primeros se les aplica una pena como consecuencia de su responsabilidad penal, los segundos reciben una medida de carácter socio-educativo. Aplicándose la Justicia Juvenil Restaurativa, la cual consiste en la atención interdisciplinaria del adolescente que comete una infracción a la ley penal, compuesta por las siguientes dimensiones: orientación diferenciada con mayor probabilidad de reinserción para el adolescente; restauración del daño a la víctima y a su familia; y restauración de la perturbación social ocasionada.

Dichas políticas se encuentran contenidas en el Plan Nacional de Prevención y Tratamiento del Adolescente en Conflicto con la Ley Penal 2013-2018, aprobado por Decreto Supremo 014-2014-JUS.

La Convención sobre los Derechos del Niño, en el artículo $40 .^{\circ}$, dispone que los Estados Partes reconocen el derecho de todo niño de quien se alegue que ha infringido las leyes penales o a quien se acuse o declare culpable de haber infringido esas leyes, que se garantice que este sea informado sin demora y directamente o, cuando sea procedente, por intermedio de sus padres o sus representantes legales, de los cargos que pesan contra él y que se dispondrá de la asistencia jurídica u otra asistencia apropiada en la preparación y presentación de su defensa; que no será obligado a prestar testimonio o a declararse culpable; que podrá interrogar o hacer que se interrogue a testigos de cargo y obtener la participación y el interrogatorio de testigos de descargo en condiciones de igualdad.

Al respecto, el Comité de los Derechos del Niño, mediante la Observación General 12, señala que el artículo $12{ }^{\circ}$ de la Convención implica que todo niño de quien se alegue que ha infringido las leyes penales o a quien se acuse o declare culpable de haber infringido esas leyes tiene el derecho de ser escuchado. Ese derecho debe respetarse plenamente en todas las etapas del proceso judicial, desde que el niño tiene derecho a guardar silencio, hasta el derecho a ser escuchado por la policía, el fiscal y el juez instructor. También es aplicable en las etapas de sentencia y resolución, así como en la aplicación de las medidas impuestas (párr. 58). Asimismo, para participar efectivamente en el procedimiento, debe ser informado de manera oportuna y directa sobre los cargos que se le imputan en un idioma que entienda, así como sobre el proceso de justicia juvenil y las medidas que podría adoptar el tribunal. El procedimiento debe desarrollarse en un ambiente que permita que el niño participe en él y se exprese libremente (párr. 60). Y las audiencias judiciales deben realizarse a puerta cerrada. Las excepciones a esta norma deben ser muy limitadas y estar claramente estipuladas en la legislación nacional y guiada por el interés superior del niño (párr. 61). 
En nuestro país, se emitió el Decreto Legislativo 1348 que aprueba el Código de Responsabilidad Penal de Adolescentes ( 7 de enero de 2017), que en el artículo $107 .{ }^{\circ}$ inciso 3 , indica, sobre la apertura del juicio y la posición de las partes, que culminados los alegatos preliminares, el juez informa al adolescente de sus derechos y le indica que es libre de manifestarse sobre la acusación o de no declarar sobre los hechos. El adolescente en cualquier estado del juicio puede solicitar ser oído con el fin de ampliar, aclarar o complementar sus afirmaciones o declarar si anteriormente se hubiera abstenido. Asimismo, el adolescente en todo momento puede comunicarse con su defensor, sin que por ello se paralice la audiencia.

Por otra parte, el Protocolo de Participación Judicial del Niño del Poder Judicial, en atención a lo dispuesto en la Convención, expresa que el adolescente de quien se alega que ha infringido las leyes penales tiene derecho a ser escuchado, el cual debe respetarse en todas las etapas del proceso judicial, sin perjuicio de su derecho a guardar silencio. Cuando se trate de la aplicación de la justicia restaurativa o la mediación penal, el adolescente infractor debe tener la oportunidad de dar su consentimiento libre y voluntario, de obtener asesoramiento y asistencia jurídica y de otros especialistas; debe ser informado de manera oportuna y directa sobre los cargos que se le imputan en un idioma que entienda, así como del proceso y las medidas que podría adoptar el juez. Dicha audiencia judicial se realizará a puerta cerrada.

\section{PARTICIPACIÓN DEL NIÑO EN EL PROCESO DE VIOLENCIA FAMILIAR Y CUANDO ES VÍCTIMA DE DELITOS O ES TESTIGO}

Según los datos estadísticos del INEI, a través de la Encuesta Nacional sobre Relaciones Sociales (ENARES 2015), el 73,8 \% de niñas y niños de 9 a 11 años, y el $81,3 \%$ de adolescentes de 12 a 17 años de edad, fueron alguna vez víctimas de violencia psicológica o física; y el 34,6 \% de adolescentes de 12 a 17 años fueron alguna vez víctimas de violencia sexual.

El artículo 19. ${ }^{\circ}$ de la Convención sobre los Derechos del Niño prescribe que los Estados Partes adoptarán todas las medidas legislativas, administrativas, sociales y educativas apropiadas para proteger al niño contra toda forma de perjuicio o abuso físico o mental, descuido o trato negligente, malos tratos o explotación, incluido el abuso sexual, mientras el niño se encuentre bajo la custodia de los padres, de un representante legal o de cualquier otra persona que lo tenga a su cargo. Esas medidas de protección deberían comprender, según corresponda, procedimientos para la intervención judicial.

El Comité de los Derechos del Niño, a través de su Observación General $13(2011)^{6}$, la Observación General $12^{7}$ y previamente en la Observación General $8(2006)^{8}$, sostiene que el niño víctima y el niño testigo de un delito deben tener la oportunidad de ejercer plenamente su derecho a expresar libremente sus opiniones de conformidad con la resolución 2005/20 del Consejo Económico y Social, Directrices sobre la justicia en asuntos concernientes a los niños víctimas y testigos de delitos (Observación General 12, párr. 62). Eso significa, en particular, que debe hacerse todo lo posible para que se consulte a los niños víctimas y/o testigos de delitos sobre los asuntos pertinentes respecto de su participación en el caso que se examine y para que puedan expresar libremente $\mathrm{y}$ a su manera sus opiniones y preocupaciones en cuanto a su participación en el proceso judicial (Observación General 12, párr. 63). Asimismo, el derecho del niño víctima y testigo también está vinculado al derecho a ser informado de cuestiones tales como la disponibilidad de servicios médicos, psicológicos y sociales, el papel del niño víctima y/o testigo, la forma en que se realizará el interrogatorio, los mecanismos de apoyo a disposición del niño cuando haga una denuncia y participe en la investigación y en el proceso judicial, las fechas y los lugares específicos de las vistas, la disponibilidad de las medidas de protección, las posibilidades de recibir reparación y las disposiciones relativas a la apelación. (Observación General 12, párr. 64)

En el Perú, el artículo $4 .^{\circ}$ del CDN señala que la niña, el niño y el adolescente tienen derecho a que se respete su integridad moral, psíquica y física y a su libre desarrollo y bienestar. Asimismo, no podrán ser sometidos a tortura ni a trato cruel o degradante.

6 Sobre el derecho del niño a no ser objeto de ninguna forma de violencia. 7 Sobre el derecho del niño a ser escuchado.

8 Sobre el derecho del niño a la protección contra los castigos corporales y otras formas de castigo crueles o degradantes. 
El artículo $17 .^{\circ}$ del Reglamento de la Ley 30364, Ley para prevenir, sancionar y erradicar la violencia contra las mujeres y los integrantes del grupo familiar, reconoce la capacidad procesal de las niñas, niños y adolescentes de denunciar actos de violencia en su agravio o en agravio de otras personas sin la necesidad de la presencia de una persona adulta. Lo cual guarda concordancia con lo dispuesto en el Protocolo Facultativo de la Convención sobre los Derechos del Niño relativo a un Procedimiento de Comunicaciones, el cual complementa los mecanismos nacionales al permitir a los niños denunciar la vulneración de sus derechos y que ellos tengan acceso a recursos efectivos en todas la instancias judiciales. Asimismo, a las recomendaciones del Comité del CEDAW, respecto a la violencia contras las niñas y las adolescentes en aplicación de la Convención sobre la Eliminación de Todas las Formas de Discriminación contra la Mujer (1979) y la Convención Interamericana para Prevenir, Sancionar y Erradicar la Violencia contra la Mujer Convención de Belem do Para (1994).

Respecto al niño víctima de delitos, el Protocolo de Participación Judicial del Niño del Poder Judicial, en el considerando 16, sigue los argumentos contenidos en la Convención, indicando que el niño puede expresar su opinión y preocupación en cuanto a su participación en el proceso judicial; tiene derecho a ser informado de la disponibilidad de los servicios médicos, psicológicos y sociales; de la forma en que se llevará a cabo el interrogatorio; los mecanismos de apoyo y su participación en la investigación y en el proceso judicial; así como de las fechas y los lugares de las vistas; la disponibilidad de medidas de protección; las posibilidades de recibir reparación y las disposiciones relativas a la apelación. En el proceso judicial están prohibidas las prácticas o procedimientos que conduzcan a la revictimización de la niña, niño o adolescente como consecuencia de las declaraciones reiteradas, interrogatorios repetidos, demoras prolongadas, la declaración frente a la persona acusada, y otros requerimientos legales que pueden ser intimidantes; se deberá transmitirle mensajes que reconozcan su valor y credibilidad y mensajes desculpabilizantes; asimismo, el juez debe expresarle que no hay respuestas correctas o incorrectas y debe tomar todas las medidas pertinentes para restringir la divulgación de información que permita identificar a los niños, niñas o adolescentes víctimas de un delito en el proceso de justicia.

Por otro lado, sobre el derecho del niño a ser oído cuando es víctima de delitos de violencia familiar, el Protocolo de Participación Judicial manifiesta, en el considerando 17, la posibilidad de que la sola declaración de la víctima sea hábil para desvirtuar la presunción de inocencia, si es que no se advierten razones objetivas que invaliden sus afirmaciones. El juez debe evaluar la ausencia de incredibilidad subjetiva, la verosimilitud del testimonio y la persistencia en la incriminación. La retractación de la víctima debe evaluarse tomando en cuenta el contexto de coerción propiciado por el entorno familiar y social próximo del que proviene la víctima y la persona denunciada.

Además, sobre el derecho del niño a ser oído cuando es testigo, el considerando 20 del Protocolo señala que toda actuación infantil deberá ser grabada en audio o imagen en su totalidad. La grabación deberá integrarse, ser transcrita y permanecer en el expediente judicial. La grabación deberá ser guardada con total confidencialidad. Asimismo, el uso de instrumentos de grabación no deberán ser ocultados al niño o niña, sino por el contrario deben mostrarse; ningún niño testigo será procesado por falso testimonio; y el juez debe adoptar las medidas de protección para que el niño, niña y adolescente preste su declaración, como evitar también el contacto directo entre los niños y las personas acusadas y dictar órdenes de alejamiento, entre otras medidas pertinentes.

\section{PARTICIPACIÓN JUDICIAL DEL NIÑO CON DISCAPACIDAD Y OTRAS CAUSAS DE VULNERABILIDAD}

El INEI, a través del informe Perú: características de la población con discapacidad (2015), según los resultados de la Encuesta Nacional Especializada sobre Discapacidad (ENEDIS), evidencia que en el país 1 millón 575 mil 402 personas padecen de alguna discapacidad y representan el 5,2\% de la población nacional. De los cuales, 10,3\% son menores de 18 años de edad. (p. 11)

Al respecto, el artículo $7 .^{\circ}$ de la Convención sobre los Derechos de las Personas con Discapacidad, aprobada y ratificada por el Estado peruano mediante la Resolución Legislativa 29127, 
desarrolla que los Estados Partes garantizarán que los niños y las niñas con discapacidad tengan derecho a expresar su opinión libremente sobre todas las cuestiones que les afecten, opinión que recibirá la debida consideración teniendo en cuenta su edad y madurez, en igualdad de condiciones con los demás niños y niñas, y a recibir asistencia apropiada con arreglo a su discapacidad y edad para poder ejercer ese derecho. Asimismo, el artículo $33 .^{\circ}$ dispone que los Estados Partes deben asegurar que las personas con discapacidad tengan acceso a la justicia en igualdad de condiciones con las demás, incluso mediante ajustes de procedimiento y adecuados a la edad para facilitar el desempeño de las funciones efectivas de esas personas como participantes directos e indirectos, incluida la declaración como testigos, en todos los procedimientos judiciales, con inclusión de la etapa de investigación y otras etapas preliminares.

Por otro lado, la Regla de Brasilia 8 recomienda que se establezcan las condiciones necesarias para garantizar la accesibilidad de las personas con discapacidad al sistema de justicia, incluyendo aquellas medidas conducentes a utilizar todos los servicios judiciales requeridos y a disponer de todos los recursos que garanticen su seguridad, movilidad, comodidad, comprensión, privacidad y comunicación.

En el Perú, el Protocolo de Participación Judicial del Niño del Poder Judicial prescribe en su considerando 18 que el juez tiene la obligación de garantizar la observancia del derecho a ser oído de los niños con discapacidad que experimenten dificultades para hacer oír su opinión. Asimismo, que estos niños deben tener disponibles los modos de comunicación que necesiten para facilitarles la expresión de sus opiniones. Disposiciones que guardan relación con la Ley 29973, Ley General de las Personas con Discapacidad y su Reglamento, y la Convención de las Personas con Discapacidad.

Además, sobre derecho a ser oído del niño en situación de vulnerabilidad, en el considerando 19 del referido Protocolo, el juez debe reconocer el derecho de opiniones de los niños pertenecientes a minorías, niños indígenas, niños inmigrantes y otros niños que no hablen el idioma español. De la misma forma, debe adoptar todas las medidas necesarias para garantizar que se ejerce el derecho a ser oído, asegurando la plena protección del niño, en especial del que se encuentra en situación de vulnerabilidad. Si la niña, el niño o el adolescente necesitan servicios de interpretación, el juez deberá proporcionar a una persona que funja de intérprete de forma gratuita.

\section{CONCLUSIONES}

La niña, niño y adolescente son sujetos plenos de derechos y titulares de todos los derechos inherentes a todas las personas; sin embargo, por razón de su edad, madurez, evolución de sus facultades e interés superior adquiere de manera progresiva la autonomía para el ejercicio de aquellos derechos.

Es una garantía procesal que la niña, niño y adolescente ejerzan su derecho fundamental a ser escuchados en el proceso judicial en el que participan o se encuentran involucrados; para lo cual el juez debe garantizar las medidas necesarias para que dicha opinión sea libre, autónoma y no manipulada por sus progenitores, entorno familiar u otros que la perturben.

Es importante que la niña, niño y adolescente reciban la información y asesoramiento jurídico, psicológico y social necesarios que les permitan el ejercicio de su derecho a ser escuchados en el proceso judicial, en un lenguaje comprensible y adaptado a sus circunstancias especiales.

En el Perú, el derecho de la niña, niño y adolescente a participar y ser escuchado en el ámbito judicial no es un derecho que está siendo garantizado de manera efectiva, porque los procedimientos judiciales no han sido diseñados considerando las características específicas de la niñez; generando como consecuencia que se presenten barreras para su acceso a la justicia, su exclusión en el proceso y que esta problemática sea valorada desde una óptica adultocéntrica.

En los últimos años se han aprobado normas, modificaciones y adecuaciones del ordenamiento jurídico nacional al sistema internacional de protección de los derechos humanos y las recomendaciones de sus máximos órganos con el fin de garantizar la protección del derecho del niño a ser escuchado; no obstante, subsisten en nuestro 
país concepciones tradicionales y culturales que vulneran este derecho humano del niño.

\section{RECOMENDACIONES}

Aprobar el nuevo Código de las Niñas, Niños y Adolescentes que desarrolle de manera expresa e integral las garantías para el ejercicio del derecho del niño a participar y ser escuchado en el proceso judicial; así como las sanciones por su incumplimiento. En atención a lo dispuesto en el artículo $12 .^{\circ}$ de la Convención y las recomendaciones de la Observación General 12 del Comité de los Derechos del Niño de las Naciones Unidas.

Establecer programas y actividades de sensibilización y promoción de la cultura jurídica para promover la participación real y efectiva de todas las niñas, niños y adolescentes en los asuntos que les afectan, en especial en los procesos judiciales en los que están involucrados.

Establecer programas de especialización y capacitación para los operadores de justicia, a fin de que reciban la formación necesaria para garantizar la participación y el derecho del niño a ser oído en el proceso judicial.

Establecer directrices e indicadores para facilitar, evaluar y supervisar la aplicación del derecho del niño a participar en asuntos pertinentes y a ser escuchado en los procesos judiciales, en aplicación de la Convención y las recomendaciones del Comité de los Derechos del Niño.

\section{REFERENCIAS}

Aguilar, B. (1996) ¿Un nuevo derecho para los niños y adolescentes? Revista de Derecho PUCP, (50), pp. 433-453. Recuperado de http://revistas.pucp.edu.pe/index.php/derechopucp/ article/viewFile/5939/5948

Beloff, M. (2004) Un modelo para armar iy otro para desarmar!: protección integral de derechos del niño vs. derechos en situación irregular. Los Derechos del Niño en el Sistema Interamericano (pp.1-45). Buenos Aires, Argentina: Editores del Puerto.

Castro, E. (2013) El acogimiento familiar frente a la desprotección familiar. Lima: Facultad de Derecho, USMP, pp.1-49.
Chunga, F. (2012). Los derechos de los niños, niñas y adolescentes y su protección en los derechos humanos. Lima, Perú: Grijley.

Cillero, M. (1998). El Interés Superior del Niño en el marco de la Convención Internacional sobre los Derechos del Niño. García Méndez, E. y Beloff, M. (comps.), Infancia, Ley y Democracia en América Latina (pp.7999). Santa Fe de Bogotá, Colombia: Temis/ Depalma. Recuperado de http://www.iin.oea.org/ Cursos_a_distancia/explotacion_sexual/Lectura4. Infancia.DD.pdf

Cillero, M. (2004) El interés superior del niño en el marco de la Convención Internacional sobre los Derechos del Niño. En Infancia, Ley y Democracia en América Latina. García Méndez, E. y Beloff, M. (comps). Bogotá, Colombia: Editorial Themis.

Comisión Interamericana de Derechos Humanos. (2002). Opinión Consultiva OC17/2002. Recuperada de http://www.corteidh. or.cr/docs/opiniones/seriea_17_esp.pdf

Comisión Interamericana de Derechos Humanos. (2013). El derecho del niño y la niña a la familia. Organización de Estados Americanos. Recuperado de https://www.oas. org/es/cidh/infancia/docs/pdf/informe-derechonino-a-familia.pdf

Comité de los Derechos del Niño. (2006). Observación General 8. Naciones Unidas.

Comité de los Derechos del Niño. (2009). Observación General 12 sobre el derecho del niño a ser escuchado. Naciones Unidas. Recuperado de www2.ohchr.org/english/ bodies/crc/docs/AdvanceVersions/CRC-CGC-12_sp.doc

Comité de los Derechos del Niño. (2011). Observación General 13. Naciones Unidas.

Comité de los Derechos del Niño. (2013). Observación General 14 sobre el derecho del niño a que su interés superior sea una consideración primordial. Naciones Unidas. Recuperado de http://www.unicef.cl/web/ informes/derechos_nino/14.pdf

Comité de los Derechos del Niño. (2016). Observaciones finales sobre los informes periódicos cuarto y quinto del Perú. Naciones Unidas. Recuperado de http://acnudh.org/wpcontent/uploads/2016/05/G1604059.pdf 
Conde, M. (2009). El acceso a la justicia de niños, niñas y jóvenes. Revista IIDH, (50), pp.191-207. Recuperado de http://www.corteidh. or.cr/tablas/r25534.pdf

Defensoría del Pueblo. (2011) Niños, niñas y adolescentes en abandono: aportes para un nuevo modelo de atención. Serie de Informes Defensoriales-Informes 153. Lima. Recuperado de http://www.defensoria.gob.pe/ modules/Downloads/informes/defensoriales/ID153.pdf

Detrick, S. (2015). El acceso a la justicia para todos los niños y niñas del mundo. UNICEF. Recuperado de http://sowc2015.unicef.org/ stories/access-to-justice-for-all-the-worldschildren/?lang=es

Fernández, W. (2016). La alienación parental como causa de variación de la tenencia. Facultad de Derecho, USMP, pp.1-27. Recuperado de http://www.derecho.usmp.edu.pe/ instituto/articulos_2016/alineacion.pdf

García, E. (2004). Legislaciones infantojuveniles en América Latina: modelos y tendencias. Infancia. De los derechos y de la justicia (pp.1-16). Buenos Aires, Argentina: Editores del Puerto.

Giménez de Allen, M. (2010). El derecho del niño/a a ser oído y el deber del juez de escuchar su opinión de manera adecuada. El Interés Superior del Niño, Tomo II (pp.95103). Asunción, Paraguay: Corte Suprema de Justicia/División de Investigación, Legislación y Publicaciones.

Instituto Nacional de Estadística e Informática (INEI). (2015). Perú: características de la población con discapacidad (2015). Recuperado de https://www.inei.gob.pe/media/ MenuRecursivo/publicaciones_digitales/Est/ Lib1209/Libro.pdf

Instituto Nacional de Estadística e Informática (INEI). (Marzo de 2017). Estado de la niñez y adolescencia (trimestre: octubre-noviembrediciembre 2016) (informe técnico N. ${ }^{\circ} 1$ ). Recuperadodel sitio de internet delINEI:https:// www.inei.gob.pe/media/MenuRecursivo/ boletines/01-informe-tecnico-n01_ninez-yadolescencia-oct-dic2016.pdf

Kemelmajer, A. y Molina, M. (2015). La participación del niño y el adolescente en el proceso judicial. Recuperado de http:// colectivoderechofamilia.com/wp-content/ uploads/2015/12/AKC-MMJ-La-participación-delniño-y-el-adolescente-en-el-proceso-judicial.pdf

Laino, S. (2012). Autonomía progresiva de la voluntad. Manual para la defensa jurídica de los derechos humanos de la infancia, (pp.1737). Montevideo, Uruguay: UNICEF.

Méndez, J. (2000). El acceso a la justicia, un enfoque desde los derechos humanos. En Thompson, José (Coordinador Académico), Acceso a la Justicia y Equidad. Estudio en siete países de América Latina. Banco Interamericano de Desarrollo e Instituto interamericano de Derechos Humanos. San José, C.R. IIDH, pp. 15-22.

Ministerio de la Mujer y Poblaciones Vulnerables. (2012). Dirección de Investigación Tutelar. Recuperado del sitio de internet del MIMP: http://www.mimp.gob.pe/ homemimp/direccion-investigacion-tutelar.php

O’Donnell, D. (1990). La Convención sobre los Derechos del Niño: estructura y contenido. Boletín del Instituto Interamericano del Niño, (230), pp.11 y ss.

\section{Normas internacionales y nacionales}

Constitución Política del Perú.

Declaración Universal de los Derechos Humanos.

Declaración de Ginebra sobre los Derechos del Niño.

Declaración de los Derechos del Niño.

Convención Americana sobre Derechos Humanos.

Convención sobre la Eliminación de Todas las Formas de Discriminación contra la Mujer.

Convención sobre los Derechos del Niño.

Convención Interamericana para Prevenir, Sancionar y Erradicar la Violencia contra la Mujer «Convención de Belem do Para».

Directrices sobre la justicia en asuntos concernientes a los niños víctimas y testigos de delitos. 
Reglas de Brasilia sobre el Acceso a la Justicia de las Personas en Condición de Vulnerabilidad (documento de sustentación). http://www.cumbrejudicial.org/c/document library/get_file?uuid=6fe6feca-4300-46b2-a9f9flb6f4219728\&groupId=10124

Convención sobre los Derechos de las Personas con Discapacidad.

Asamblea General de las Naciones Unidas. (2010). Directrices sobre las modalidades alternativas de cuidado de los niños. Recuperado de https://www.unicef.org/spanish/ videoaudio/PDFs/100407-UNGA-Res-64-142. es.pdf

Protocolo Facultativo de la Convención sobre los Derechos del Niño relativo a un Procedimiento de Comunicaciones.

Código de los Niños y Adolescentes.

Código de Responsabilidad Penal de Adolescentes.

\section{Código Civil.}

Ley 30466, Ley que establece los parámetros y garantías procesales para la consideración primordial del interés superior del niño.

Ley 30364, Ley para prevenir, sancionar y erradicar la violencia contra las mujeres y los integrantes del grupo familiar y su Reglamento.
Decreto Legislativo 1297 para la protección de niñas, niños y adolescentes sin cuidados parentales o en riesgo de perderlos.

Proyecto de Ley 495/2011-CR, sobre el nuevo Código de las Niñas, Niños y Adolescentes.

Ley 29973, Ley General de la Personas con Discapacidad y su Reglamento.

Protocolo de Participación Judicial del Niño, Niña y Adolescente, aprobado por la Resolución Administrativa 228-2016-CE-PJ.

\section{Planes nacionales}

Ministerio de la Mujer y Poblaciones Vulnerables. (2012). Plan Nacional de Acción por la Infancia y la Adolescencia 2012-2021. Recuperado de http://www.mimp.gob.pe/webs/ mimp/pnaia/pdf/Documento_PNAIA.pdf

Ministerio de Justicia y Derechos Humanos. (2013). Plan Nacional de Prevención y Tratamiento del Adolescente en Conflicto con la Ley Penal 2013-2018. Recuperado de https:// www.minjus.gob.pe/wp-content/uploads/2015/08/ plan-nacional-prevencion.pdf

Plan Nacional de Acceso a la Justicia de Personas en Condición de Vulnerabilidad Poder Judicial 2016-2021. 